\title{
Targeting Global Environmental Challenges by the Means of Novel Multimodal Transport: Concept of Operations
}

\author{
Vilius Portapas \\ Department of Engineering Design \\ and Mathematics \\ University of the West of England \\ Bristol, United Kingdom \\ vilius.portapas@uwe.ac.uk \\ Daniela Paddeu \\ Department of Geography \\ and Environmental Management \\ University of the West of England \\ Bristol, United Kingdom \\ daniela.paddeu@uwe.ac.uk
}

\author{
Yaseen Zaidi \\ Department of Engineering Design \\ and Mathematics \\ University of the West of England \\ Bristol, United Kingdom \\ 0000-0002-9735-8855 \\ Agustin Valera-Medina \\ School of Engineering \\ Cardiff University \\ Cardiff, United Kingdom \\ valeramedinaa1@cardiff.ac.uk
}

\author{
Jerzy Bakunowicz \\ and Mathematics \\ Bristol, United Kingdom \\ jerzy.bakunowicz@uwe.ac.uk \\ Arnaud Didey \\ Neoptera Aero Ltd \\ Smart Ports Systems Ltd \\ Bristol, United Kingdom \\ arnaud@neoptera.aero
}

Department of Engineering Design

University of the West of England

\begin{abstract}
Novel modes of transport form the basis of environmentally friendly and economically efficient transport system of the future. This paper introduces the feasibility study of a Dock to Dock (D2D) use case, combining aspects of route development and infrastructure definition for the transport of goods in South West England and South Wales. The proposed system makes use of new, more flexible and environmentally friendly means of transport, such as electric Vertical Take-Off and Landing (eVTOL) aircraft and electric Autonomous ZeroEmission (eAZE) vessels. To meet the environmental targets set out for the transport sector, the use of alternative hydrogenbased fuels is investigated for air, surface and marine vehicles. Logistics, regulations and infrastructure required for the safe and efficient production and distribution of such low-emission energy vectors is also considered. Digital twin of the system is proposed to study its safety and viability, while the analysis of energy requirements is proposed to inform policy makers and define the necessary infrastructure to meet future emission-free transport energy needs.

Index Terms - ammonia, digital twin, Dock to Dock, D2D, eAZE, eVTOL, hydrogen power, multimodal transport system, SMAHRT, Smart-Multiports
\end{abstract}

\section{Introduction}

Numerous global initiatives aim to significantly reduce $\mathrm{CO}_{2}$ and $\mathrm{NO}_{\mathrm{x}}$ emissions of separate components and overall chain of transport system [1], [2]. This is inconceivable without the new modes of transport as well as alternative fuels.

For the aviation sector the International Air Transport Association (IATA) laid out the technological roadmap [3] that should lead to the successful achievement of the

Research described in this paper has been funded by the UKRI Future Flight Challenge competition. Project title: "Dock to Dock (D2D) Hydrogen eVTOL Freight Transportation" (Ref.: 71499). targets. The International Civil Aviation Organisation (ICAO) - that has setup the Carbon Offsetting and Reduction Scheme for International Aviation (CORSIA) - noted "that the introduction of sustainable aviation fuels (SAF) is one of the measures that can contribute significantly to ICAO's climate objective" [4].

Similarly the marine industry is also taking actions to reduce its carbon footprint and lower its emissions. The International Maritime Organisation (IMO) targets a 70\% reduction in $\mathrm{CO}_{2}$ emissions with an overall $50 \%$ reduction in the green house gases emissions by 2050 [5].

Considering the above points, it is clear that the currently operating fossil fuels based transport system will not meet the environmental goals. Hence, the consortium of Cardiff University, University of the West of England, Neoptera Aero Ltd and Smart Ports Systems Ltd - the organisations based in South West England and South Wales across the Severn estuary - has proposed to evaluate a variety of freight transport options and use cases (air, road, sea, rail) in an effort to define the energy requirements of the future, low-emission transport modes.

Part of the Innovate UK Future Flight Challenge (FFC) competition, the Dock to Dock (D2D) project focuses on the combined aspects of route development, vehicle performance and the associated infrastructure. It is aimed at investigating the viability and efficiency of a multimodal zero-emission transport network and identify future clean energy requirements to meet ever increasing needs of future battery and hydrogen powered vehicles. In particular, the project focuses on airborne (unmanned cargo electric Vertical Take-Off and Landing aircraft - eVTOL) and waterborne (electric Autonomous Zero-Emission vessel - 
eAZE) alternatives to ground transportation also powered by other hydrogen vectors such as ammonia.

The proposed air and water routes between Avonmouth, UK and Cardiff, UK docks have been identified as a valid use case for for the operational example and are shown in Fig. 1.

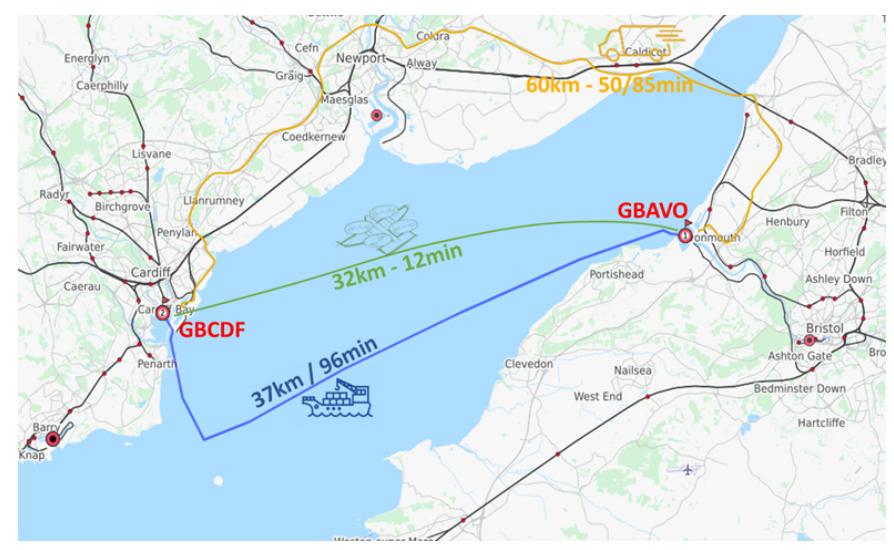

Fig. 1. Land, sea and air routes between Avonmouth and Cardiff docks. (Source: Google Maps)

This paper lays out the proposed concept of operations and reviews its peculiarities through the analysis of: 1) usual road traffic patterns between Avonmouth and Cardiff docks; 2) introduction of the concept of operations in terms of potential scenarios, vehicles to be used and ground infrastructure; 3) verification of it in terms of viability, safety and energy requirements; 4) future plans to develop the concept.

\section{Issues with the Usual Traffic Flow Between Avonmouth and Cardiff Docks}

Around the world, ground road transport is becoming increasingly congested. Moving goods by air or water ways may alleviate road traffic or, as a minimum, slow its growth. However, in order to assess alternative modes of freight/goods transport, it is first necessary to quantify the typical flow of traffic between ports and transport hubs in the South West England and South Wales, UK.

The data of the usual road traffic was acquired from the road traffic statistics database [6] curated by the UK Department for Transport (DfT). The database provides average daily traffic statistics for the regional and national road networks across the UK. DfT ensures the highlevel robustness of the figures, which are also reported as national statistics, hence being a respectable source of data for the analysis presented below.

\section{A. Usual Traffic Patterns}

The distance between Avonmouth and Cardiff docks is $60 \mathrm{~km} .25 \%$ of that distance runs through urbanised territories, such as Bristol, Newport and Cardiff. Around 1600 light goods vehicles (LGVs) and 1250 heavy goods vehicles (HGVs) use this route every day and produce around $411 \mathrm{~kg}$ of $\mathrm{NO}_{\mathrm{x}}$ and $194 \mathrm{~kg}$ of $\mathrm{CO}_{2}$ emissions per day. Transfer of the goods to other means of transport, e.g. airborne or waterborne, would have a desirable effect on the environment, hence the choice of this particular transport corridor for the project described in this paper.

\section{B. Operating Scenarios Considered}

In order to assess the D2D use case and its environmental, economical and energy implications, two scenarios are considered:

- Transporting high-value, time sensitive goods; such goods are assumed to be transported either using battery-powered LGVs or unmanned eVTOLs, considering a typical payload of 500kg / 120 parcels;

- Transporting bulky, non time sensitive goods; such goods are assumed to be transported either using fuelcell powered HGVs or eAZEs, considering a typical payload of one TEU (twenty-foot equivalent unit container) / 14 tonnes net.

\section{Proposed Concept of Operations}

To mitigate the issues mentioned above, the consortium is proposing to divert part of the goods carried between Avonmouth and Cardiff docks by road to the means of the following modes of transport:

- Airborne, using eVTOLs;

- Waterborne, using eAZEs.

Both airborne and waterborne vehicles aim to make use of hydrogen to generate the electricity needed to run electric motors.

\section{A. eVTOL Aircraft}

Traditional forms of VTOL aircraft, such as conventional helicopters and convertible aircraft (e.g. tilt-rotor aircraft) have been in operation for a considerable time. However, both types were used whether for commuting of wealthy individuals or for military and public services. With the recent advance in engineering technologies, it is a common belief that VTOLs are becoming more affordable to manufacture and operate. Moreover, introducing electric VTOLs would also reduce the environmental impact of aviation. Hence, the choice of eVTOL aircraft for the goal of this project.

eVTOLs bring many economic advantages versus the ground transportation, such as reduced travel time, flexible routing. For example, the distance between Avonmouth and Cardiff docks is around $32 \mathrm{~km}$ by air, which is almost $50 \%$ less than the distance of the ground route. Moreover, the air route lies fully over the water, hence reducing the footprint of this transport corridor. Considering the average flight velocity of around $185 \mathrm{~km} / \mathrm{h}$ (the usual cruise velocity of a similar size Cessna 172 aeroplane) the time needed for the trip reduces even more.

More than 200 eVTOL concepts has been developed up to now. Neoptera Aero has been researching on eVTOL concepts and has proposed a modular eVTOL 
system. The system features a detachable cabin, which accommodates the energy source (e.g. batteries and/or hydrogen fuel-cells) together with the payload to permit faster turnaround times. Other similar concept is Elroy Air's Chaparal, which has been developed for logistics missions. Both concepts are show in Fig. 2.

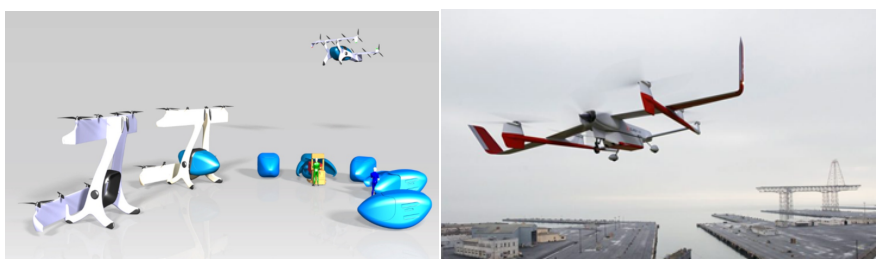

Fig. 2. eVTOLs developed by Neoptera Aero (left) and Elroy Air (right). (Source: Neoptera Aero and Elroy Air)

\section{B. Electric Waterborne Transport}

As part of the D2D project, preliminary sizing and top level modelling and simulations has been carried out for a variety of vessel propulsion systems. The scope of the study was to investigate the systems, suited for vessels of around $3000 \mathrm{t}$ of deadweight that would need around 1.5-3.0 MWe of power. The study has indicated that battery powered vessels can be remarkably competitive to operate on short routes (typically no more than $10 \mathrm{~h}$ of sailing time) when compared with both traditionally (heavy fuel oil (HFO) or liquefied natural gas (LNG)) and hydrogen (dual-fuel internal combustion and protonexchange membrane fuel cells (PEMFC)) powered vessels.

Full battery powered vessels are already operating around the world. For example, the Yara Birkeland, commissioned in 2017 and launched in February 2020, is shown in Fig. 3 and sails routes of up to 30 nautical miles in Norway.

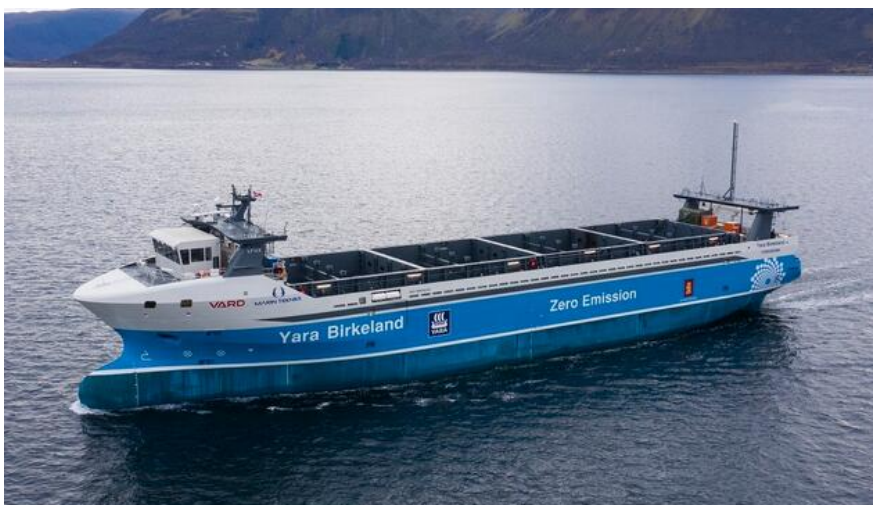

Fig. 3. Fully battery powered ship Yara Birkeland. (Source: Yara International)

With the sustainability of large scale and widespread use of electric batteries still in question, hydrogen fuelled vessels are also being developed with various initiatives taking place in other parts of Europe. Havyard Group is working with PowerCell Sweden AB, Linde and system integrator Norwegian Electrical Systems to retrofit a passenger ferry, operated by Havila and shown in Fig. 4, by 2023 .
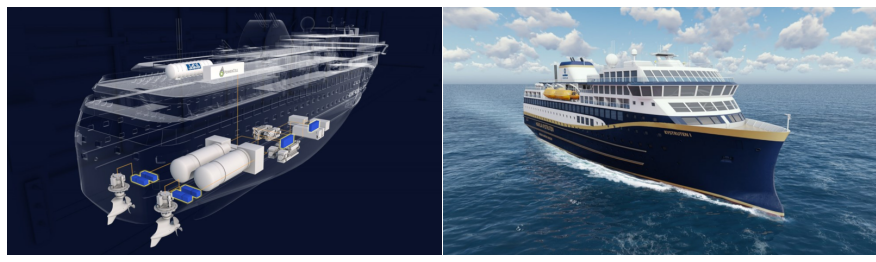

Fig. 4. Havila 3.2MW hydrogen fuel cell ferry. (Source: Havyard Group)

Zulu Associates are working to develop zero-emission energy solutions for their short sea vessels, ZULU MASS, shown in Fig. 5, in consultation with Smart Ports Systems Ltd.

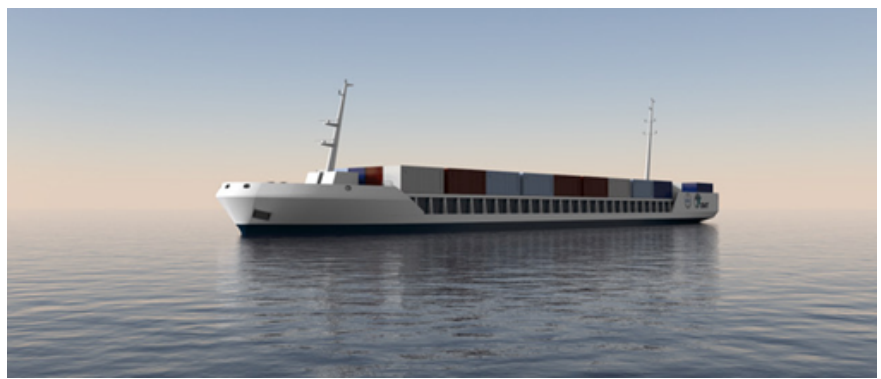

Fig. 5. ZULU MASS vessel. (Source: Zulu Associates)

\section{Hydrogen Infrastructure}

Hydrogen, the most common molecule in the universe, is one of the chemicals that could relegate fossil fuels. However, it is not typically present in its pure form, hence must be derived from other sources. Currently hydrogen is predominantly obtained from fossil fuels, typically via steam methane reforming, hence resulting in grey (without carbon capture and sequestration (CCS)) or blue (with CCS) hydrogen. However, these are increasingly being replaced by green hydrogen produced with very low emissions by water electrolysis using renewable electricity.

Hydrogen possess numerous paths for its production, distribution and consumption that present a complex variation and trade-off between costs, emissions, scalability and requirements [7]. In line with this, the area of the South West England and South Wales is expanding its interest in the use of hydrogen not only as a medium to store renewable energy, but also as an e-fuel capable of delivering heat, cooling, power and propulsion, hence being a perfect choice for the demonstration of the proposed transport system.

One of the main drawbacks of hydrogen being used in transport system is its very low volumetric energy 
density (even when liquefied or compressed to very high pressures), making it difficult to transport and store. Liquid hydrogen exhibits volumetric energy density of $8.4 \mathrm{GJ} / \mathrm{m}^{3}$ compared to $34.9 \mathrm{GJ} / \mathrm{m}^{3}$ of kerosene [8], hence requiring around four times more storage volume to produce the same amount of energy. Its propensity to leak and the issue of boiloff further increase complexity of its logistics.

Liquid ammonia $\left(\mathrm{NH}_{3}\right)$, on the other hand, exhibits volumetric energy density of $13.6 \mathrm{GJ} / \mathrm{m}^{3}$ at $15^{\circ} \mathrm{C}$ [8]. This presents a convenient and more energy efficient vector for the storage and transport of hydrogen. Hence, this way of hydrogen use is being pursued by Cardiff University and is of interest to Smart Ports Systems.

Domestic production of green hydrogen in the South West England and South Wales may be complemented by green hydrogen produced in regions of the world benefiting from an abundance of renewable energy. Such regions are the Middle East (NEOM project by Air products) or Australia (Asian Renewable Energy Hub). The hydrogen from these regions may be imported into South Wales in the form of green ammonia via a well established supply chain used for over a century by the chemical and fertiliser industries.

\section{Ground Infrastructure}

The ground infrastructure is a key element in hydrogen distribution system. Project partner, Smart Ports Systems, has been developing Smart-Multiports in order to cater for the energy needs of all forms of transport vehicles converging at seaports (sea-side and land-side) and airports (air-side and land-side), see Fig. 6.

The energy supplied at ports may be in the form of:

- high-power direct-current electricity; this could be used to recharge readily available battery electric vehicles;

- compressed fuel-cell grade hydrogen; this could be used to refuel fuel-cell based electric vehicles;

- a combination of the above; this could be used to refuel hybrid electric eVTOLs.

To accommodate the above mentioned modularity, Smart-Multiports are focused around the Scalable \& Modular Ammonia to Hydrogen Refuelling Terminals (SMAHRT), developed by Smart Ports Systems and shown in Fig. 7. SMAHRT has been engineered in a way to enable it to deliver fuel-cell grade hydrogen and power. Moreover, SMAHRT uses ammonia as a convenient vector for the distribution of hydrogen.

\section{E. Proposed Route}

The shortest distance between Avonmouth and Cardiff docks is by or over the waters of the Severn estuary, which may be travelled either by water or by air, as shown in Fig. 1. Although the air travel seems faster, the waterborne transport could carry larger goods, all in all alleviating the loading on the roads. The water route, depicted by blue
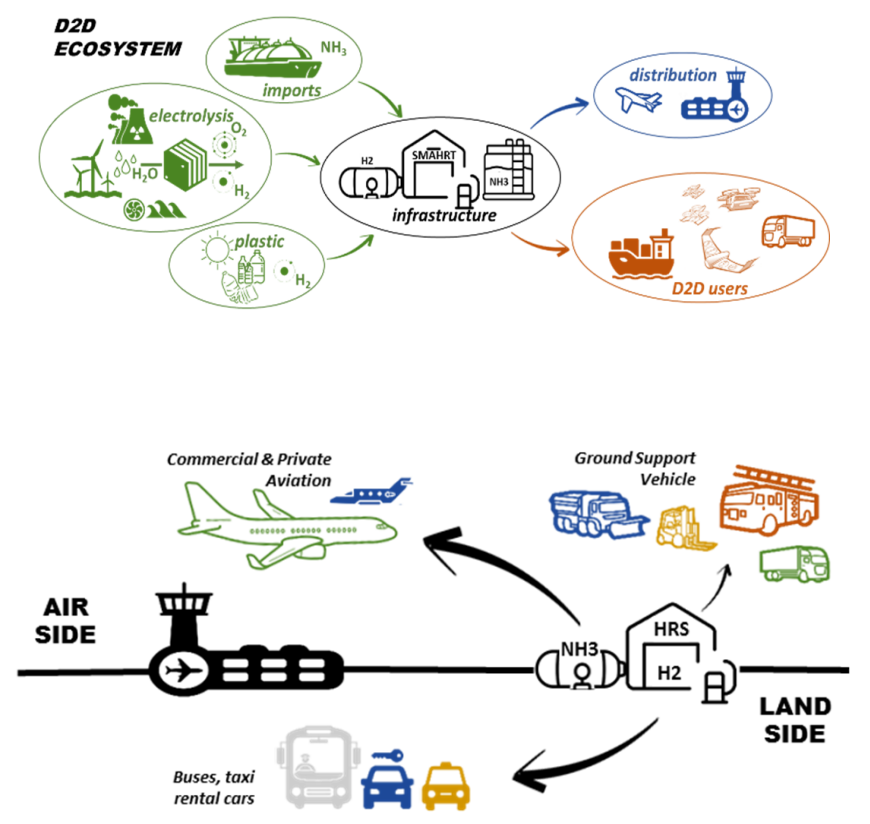

Fig. 6. Dock to Dock ecosystem (top) and $\mathrm{H}_{2}$ refuelling infrastructure at airports (bottom). (Source: Neoptera Aero / Smart Ports Systems)

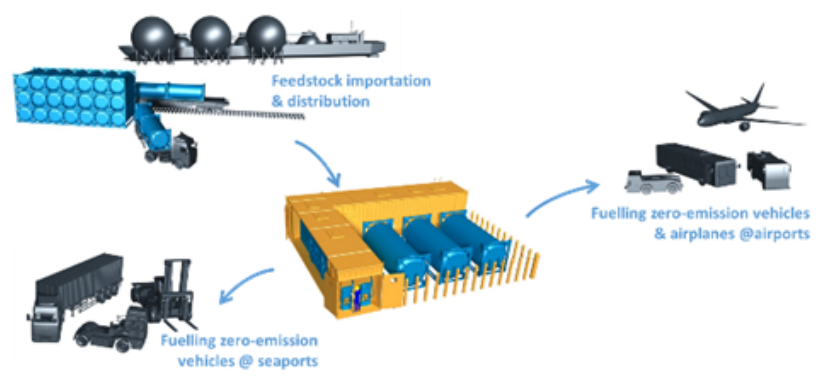

Fig. 7. SMAHRT infrastructure. (Source: Smart Ports Systems)

line in Fig. 1, shows a kink that is a peculiarity appearing due to the low and high tides causing restrictions of the nautical navigation. Apart from this feature the nautical navigation is well defined as both docks are well developed and used by numerous small and medium size ships. Hence, the further discussion elaborates on the air route.

The airspace along the route from Avonmouth to Cardiff (green line in Fig. 1) is organised in classes D and G airspace, depending on the flight altitude, and has been visualised in Fig. 8, based on the data from [9]. Two classes provide options for both controlled (class D) and uncontrolled (class G) flights. Considering safety, the best option for the flight would be in class D airspace. However, this would impose certain restrictions, such as submitting 


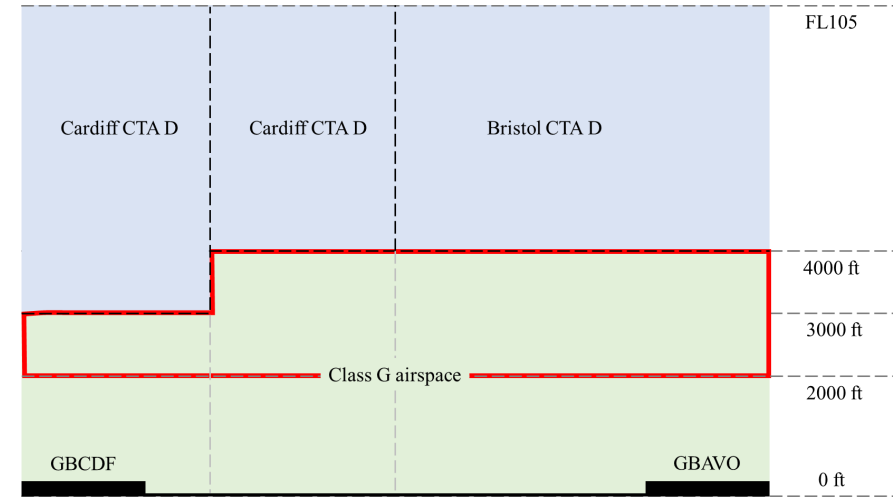

Fig. 8. Airspace composition between Avonmouth and Cardiff docks with red line showing the preferred airspace for the flight demonstration.

a flight plan, following instructions from the air traffic controllers and installing a transponder onboard. On the other hand, class $\mathrm{G}$ airspace provides freedom for routing, hence allowing straight line flights, while imposing the responsibility to fly safely entirely on a pilot. Moreover, existing surveillance capabilities, e.g. Bristol radar, could provide flight monitoring service if the flight altitude is above $2000 \mathrm{ft}$, hence within the class $\mathrm{G}$ airspace. Thus, class $\mathrm{G}$ and altitude between $2000 \mathrm{ft}$ and $3000-4000 \mathrm{ft}$ is the preferable airspace for flight demonstrations within the scope of this project.

The current regulation [10] does not allow flying unmanned flying vehicles beyond the visual line of sight (BVLOS) in a part of the airspace shared with other users. Each operation of this kind requires the airspace to be segregated and the aircraft to be isolated from other flying objects. These constraints make the analysis purely theoretical if eVTOLs fly in the fully autonomous mode. The class G airspace of concern between Avonmouth and Cardiff is moderately occupied by light aeroplanes and helicopters. The current airspace modernisation strategy [11] envisages integrating the new technologies into the airspace system, so this part of airspace may look differently in the nearest future. Existing surveillance infrastructure, monitoring the areas over the Severn estuary, may enable the autonomous flights while flying above 2000 $\mathrm{ft}$.

The eVTOL characteristics are close to the rotorcraft regarding the manoeuvres close to the ground, such as take-off, hover and landing. Hence, they may operate from any convenient location. However, scheduled or repetitive operations, which would be the case for the D2D system, must be conducted from certified sites, called heliports or helipads. Both Avonmouth and Cardiff have helipads on the shore lines, close to the industrial areas, hence providing quick access to the goods and a flight path fully over the water. Such an arrangement adds additional level of safety for the demonstration of the proposed concept.
IV. Verification of the Proposed Concept of Operations

Having the concept of operations defined, the two step verification process has been proposed:

1) Development of a digital twin of the system in order to assess its safety and viability.

2) Estimation of the energy requirements to ensure the system's capability to operate between the two docks.

\section{A. Digital Twin of the Airborne System}

Digital twins are gaining popularity within the aerospace engineers' community, as the aircraft and other related systems have become more complex than ever [12], [13]. The digital twin of an airborne platform is aimed at time-based mission analysis and design. Hence, within the scope of this project, a flight profile transiting between two points, i.e. Avonmouth and Cardiff helipads, will be analysed to identify the optimal one and define profiles of separate segments of flight, i.e. vertical takeoff and landing, climb and descent, and straight level flight. The terrain within the twin will be supported with ARINC424 runways, navaids and waypoints. This will allow to characterise the flight profile for the flight time and/or the ground distance. Hence, a trade-off analysis will be done based on the ground speed, flight path angle, climb and descent rates, and wind and air density models.

The digital twin will consider avionics performance, e.g. high fidelity modelling of radio signal propagation, free space path loss due to the fixed antenna orientation during pitch motion of the eVTOL and availability of GPS during the route. A search and track radar will be attached to the vehicle model to increase situational awareness during the route. Detection performance will be assessed under the rain, fog, cloud coverage and absorption propagation effects and channel fading. The functional architecture of the transmitter will take into account the field of view, beam patterns, polarisation, RF power, antenna gain and transmission losses including ground reflectivity.

\section{B. Energy Requirements}

Estimation of energy requirements, important parameters of every dynamic system, replaces estimation of economic efficiency, as the economic characteristics of the system are challenging to generate. Hence, the consortium is characterising air, ground and sea routes, and developing of several vehicle cost and performance models to identify the energy requirements of each of transport modes. The particular interest within the scope of the D2D project are:

- Electrical power capacity (in kWh) required at SmartMultiports to re-charge battery powered vehicles, in particular electric vans, electric vessels and eVTOLs.

- Hydrogen fuel requirements (in $\mathrm{kg}$ of $\mathrm{H}_{2}$ ) required at ports to re-fuel fuel-cell vehicles (fuel-cell electric vehicles, in particular lorries), dual-fuel vehicles (diesel 
and hydrogen internal combustion), hydrogen fuel air vehicles (in particular regional aircraft).

The specification of future low-emission energy requirements will inform Smart Ports Systems infrastructure design, local policy makers and the master planning of seaports and airports in the region.

\section{Conclusions and Further Work}

The paper has proposed a novel multimodal transport system to be tested within the regions of South West England and South Wales. The system is aimed to improve the connectivity across the Severn estuary by introducing airborne and waterborne vehicles to carry good between Avonmouth and Cardiff docks. The backbone of the proposed multimodal system consists of hybrid eVTOL (airborne) and eAZE (waterborne), fuelled by the hydrogen, hence helping to achieve the global environmental goals. As the liquid hydrogen exhibits very low volumetric density, Smart Ports Systems has proposed use of ammonia through their developed SMAHRT infrastructure. The study on the potential air and water routes between the docks identified 32-37 km distance compared to $60 \mathrm{~km}$ distance by road. Moreover, the straight line flights could take place within the uncontrolled airspace and benefit from current local surveillance capabilities. The digital twin of the airborne system and the study of overall energy requirements have been proposed to ensure the safety and viability of the multimodal e-fuel-driven transport system.

To successfully accomplish the D2D project, the following tasks will be carried out by March 2022:

- Dock to Dock use case, economics and environmental assessment;

- Definition of the hydrogen infrastructure requirements for airports and ports;

- eVTOL performance assessment;

- Development of a digital twin of the airborne system.

\section{Acknowledgement}

The authors of this paper appreciate the contributions from the Smart Ports Systems, in particular its CEO Alan Robinson. Smart Ports Systems is an integral part of the D2D project and SMAHRT system is a key element of the proposed concept of operations.

\section{References}

[1] EC, 'Flightpath 2050: Europe's vision for aviation', European Commission, Luxembourg, 2011.

[2] ATAG, 'Waypoint 2050', Air Transport Action Group, Geneva, Switzerland, Sep. 2020.

[3] IATA, 'IATA technology roadmap', International Air Transport Association, Montreal, Canada, Jun. 2013.

[4] ICAO, 'Declaration of The Second Conference On Aviation And Alternative Fuels (CAAF/2)', International Civil Aviation Organisation, Mexico City, Mexico, Oct. 2017.

[5] IMO, 'Initial IMO Strategy on Reduction of GHG Emissions From Ships', International Maritime Organization, London, UK, Resolution MEPC.304(72), Apr. 2018.

[6] Department for Transport, 'Road traffic statistics'. https://roadtraffic.dft.gov.uk/ (accessed Apr. 07, 2021).
[7] I. Staffell, D. Scamman, A. V. Abad, P. Balcombe, P. E. Dodds, P. Ekins, N. Shah, and K. R. Ward, 'The role of hydrogen and fuel cells in the global energy system', Energy \& Environmental Science, vol. 12, no. 2, pp. 463-491, 2019, doi: 10.1039/C8EE01157E.

[8] Y. Bicer and I. Dincer, 'Life cycle evaluation of hydrogen and other potential fuels for aircrafts', International Journal of Hydrogen Energy, vol. 42, no. 16, pp. 10722-10738, 2017, doi: 10.1016/j.ijhydene.2016.12.119.

[9] CAA, 'UK Aeronautical Information Publication (AIRAC 03/2021)', UK Civil Aviation Authority, Crawley, UK, CAP 032, Feb. 2021.

[10] CAA, 'Unmanned Aircraft System Operations in UK Airspace - Guidance', UK Civil Aviation Authority, Crawley, UK, CAP 722, Nov. 2020.

[11] CAA, 'Airspace Modernisation Strategy', UK Civil Aviation Authority, Crawley, UK, CAP 1711, Dec. 2018.

[12] E. H. Glaessgen and D. S. Stargel, 'The Digital Twin Paradigm for Future NASA and U.S. Air Force Vehicles', presented at the 53rd AIAA/ASME/ASCE/AHS/ASC Structures, Structural Dynamics and Materials Conference, Honolulu, HI, Apr. 2012, doi: $10.2514 / 6.2012-1818$

[13] H. Aydemir, U. Zengin, and U. Durak, 'The Digital Twin Paradigm for Aircraft Review and Outlook', presented at the AIAA Scitech 2020 Forum, Orlando, FL, Jan. 2020, doi: $10.2514 / 6.2020-0553$. 